\title{
Uma nova centralidade para Macaé
}

Une nouvelle centralité pour Macae

Una nueva centralidad para Macaé

A new centrality for Macae

\section{Glauco Lopes Nader}

\section{Q OpenEdition \\ Journals}

\section{Edição electrónica}

URL: http://journals.openedition.org/espacoeconomia/6197

DOI: 10.4000/espacoeconomia.6197

ISSN: 2317-7837

\section{Editora}

Núcleo de Pesquisa Espaço \& Economia

\section{Refêrencia eletrónica}

Glauco Lopes Nader, « Uma nova centralidade para Macaé », Espaço e Economia [Online], 14 | 2019,

posto online no dia 12 agosto 2019, consultado o 04 setembro 2019. URL : http://

journals.openedition.org/espacoeconomia/6197 ; DOI : 10.4000/espacoeconomia.6197

Este documento foi criado de forma automática no dia 4 Setembro 2019.

(C) NUPEE 


\title{
Uma nova centralidade para Macaé
}

\author{
Une nouvelle centralité pour Macae \\ Una nueva centralidad para Macaé \\ A new centrality for Macae
}

Glauco Lopes Nader

\section{INTRODUÇÃO}

1 O desenvolvimento do Modo de Produção Capitalista ocorre de forma diferenciada nos diversos momentos históricos e territórios onde se põe em movimento o desenvolvimento das suas forças produtivas e relações de produção. Cada lugar é impactado diferentemente de acordo com suas características e peculiaridades históricas, sociais, econômicas, políticas e territoriais. Nesse sentido, alguns territórios ocupam importância e sofrem consequências singulares devido à dinâmica própria do avanço do capitalismo. 0 estado do Rio de Janeiro (ERJ) e, particularmente, a região conhecida como Bacia de Campos (BC) foram palcos de algumas transformações concernentes ao movimento das relações de produção e das forças produtivas desse modo de produção vibrante e em constante transformação.

2 Apesar da crise do setor petrolífero vivenciada nos últimos anos, houve uma disseminação do crescimento da economia fluminense desde que a economia do petróleo tornou-se o novo eixo dinâmico do ERJ. Santos (2005) reforça que os benefícios desse movimento transbordam a partir de Macaé para outros municípios da BC e para a Baixada Litorânea, chegando até mesmo às economias dos municípios da RMRJ. Podemos apontar que os efeitos positivos do crescimento das atividades e da produção petrolíferas atingem todas as regiões do ERJ, pois há um grande volume de repasses diretos e indiretos de recursos oriundos da distribuição dos royalties e das participações especiais em percentuais diferenciados para praticamente todos os 92 municípios fluminenses. Além da área fiscal, o volume de contratações de bens e serviços pela Petrobras e pelas empresas do setor contribui para a dinâmica fluminense com a mobilização de diversos segmentos econômicos. 
Geralmente até 2005, os investimentos concentravam-se no elo de Exploração e Produção Offshore (E\&P) na BC com seu tradicional epicentro em Macaé. Desde aquele momento, ocorreram a intensificação das atividades nos outros elos dessa cadeia produtiva através de investimento, tais como: a expansão do Centro de Pesquisa e Desenvolvimento da Petrobras (CENPES), na Ilha do Fundão; a ampliação da REDUC; a retomada e depois o arrefecimento da indústria naval em Niterói e Angra dos Reis; o incremento das atividades de E\&P na BC por outras operadoras, a construção do COMPERJ, em Itaboraí ${ }^{1}$ a construção do Porto do Açu, em São João da Barra, a consolidação da Bacia de Santos (BS) como a maior província produtora de petróleo do país e com o aumento do número de empresas petrolíferas atuando no país.

4 Nesse contexto, o objetivo deste trabalho é investigar o conteúdo e o significado da nova centralidade econômica e territorial de Macaé diante dos novos empreendimentos na região da $\mathrm{BC}$ e das novas fronteiras exploratórias. Resumidamente, pretenderemos evidenciar que há necessidade de um novo posicionamento e/ou de uma nova centralidade econômica e territorial de Macaé em relação ao reconhecimento como centro da indústria petrolífera no Brasil. Essa nova centralidade deverá ser construída a partir das características de um novo momento histórico vivenciado pelo país, pelo ERJ e pela própria indústria de $P \& G$. Essa construção dar-se-á a partir de uma espacialidade própria, que considera alguns aspectos: 1) o novo momento político e econômico vivenciado pela economia brasileira; 2) a superação dos anos de crise profunda experimentados pelo ERJ e, principalmente, pela região da $\mathrm{BC}$ e Macaé; 3) as mudanças no marco legal do setor de P\&G que possibilitam a entrada de novos players; 4) os investimentos projetados para a indústria de $\mathrm{P} \& \mathrm{G}$ no Brasil; 5) o posicionamento mais agressivo e competitivo dos municípios circunvizinhos de Macaé na busca por investimentos e pela atração de empresas.

5 Diante desse cenário, a ideia é analisar uma possível perda de centralidade de Macaé diante da identificação de dois movimentos, a saber: 1) um mais amplo, a partir de investimentos e novas fronteiras exploratórias fora da BC; e 2) outro de âmbito regional configurando um movimento interno na própria $\mathrm{BC}$ de "transbordamento" da dinâmica econômica dessa indústria para além das fronteiras macaenses em direção aos outros municípios, como Rio das Ostras e Campos dos Goytacazes.

6 Especificamente, investigaremos como o Modo de Produção Capitalista desenvolveu sua característica de construção de uma espacialidade própria a partir do desenvolvimento das forças produtivas e das relações de produção na região da BC. De forma mais concreta, investigaremos o significado da centralidade exercida por Macaé em relação ao conjunto da economia do ERJ, como locus do desenvolvimento da indústria de petróleo e gás no Brasil. No tocante à relevância do trabalho, destacamos algumas questões: 1) a importância de realizar um trabalho sobre o desenvolvimento da indústria de petróleo e gás natural devido à preponderância que possui para a economia dos municípios produtores da $\mathrm{BC}$ e para todo o ERJ; 2) essa fonte energética historicamente ocupa espaço relevante nas disputas geopolíticas mundiais; 3 ) as perspectivas de investimentos na indústria de petróleo e gás natural $(\mathrm{P} \& \mathrm{G})$ para os próximos anos; 4$)$ as características inerentes do desenvolvimento da atividade petrolífera tornam seus impactos extremamente relevantes para as dinâmicas econômica e social dos territórios em que se instala; e 5) apesar dos esforços desempenhados por alguns autores que atuam em universidades na região da $\mathrm{BC}$ e, mesmo fora dela, ainda perdura a percepção de escassez 
de literatura sobre os impactos econômicos, sociais, políticos e espaciais provocados pela instalação da indústria de petróleo e gás nessa região e no ERJ.

\section{A EXIGÊNCIA DE UMA ESPACIALIDADE PRÓPRIA DO CAPITALISMO}

7 A robutez teórica do Materialismo Histórico permite compreender profundamente as facetas e as nuances do desenvolvimento do Modo de Produção Capitalista (MPC). Diversos autores dessa corrente ao longo do século XX contribuíram para a compreensão de sua dinâmica espacial. Entretanto, dois autores destacam-se pela singularidade de suas contribuições. São eles os franceses Henry Lefèbvre e Alain Lipietz.

8 O MPC é caracterizado por revolucionar constantemente os meios de produção, as relações de produção e, por conseguinte, todas as relações sociais. Verifica-se um processo de transformação contínua em todas as esferas da vida². Há uma necessidade crescente pela valorização do capital através da aquisição de novos mercados e do aumento da produtividade do trabalho. Possui como dimensão essencial a centralidade nas relações econômicas e na dinâmica marcada pelo conflito e pela divisão. Ele não é somente caracterizado pela 'separação dos produtores de seus meios de produção, monopolizados pela classe capitalista'. É, antes de tudo, um modo de produção onde 'o trabalho social se apresenta como soma de trabalhos privados, efetuados independentemente uns dos outros', e onde a alocação do trabalho e a realocação do produto entre as unidades independentes se efetuam por relações mercantis. Marx consagrou a primeira seção de 0 Capital a esta primeira característica (LIPIETZ, 1988: 27).

9 O aspecto fundamental do Materialismo Histórico de Marx e Engels é o reconhecimento da centralidade da forma material da produção e da reprodução das relações sociais. $O$ trabalho torna-se condição sine qua non da existência da vida social através da apropriação da natureza pelos homens. Sendo assim, o trabalho e a apropriação de parte de seu resultado por uma classe que não o realiza é a garantia fundamental da lógica de reprodução dessa sociedade. Assim, esta é a fundamentação marxista do mundo capitalista, concepção materialista, na medida em que constata e extrai daí os significados devidos, a centralidade da produção e do trabalho, como as mediações fundantes da sociedade (PAULA, 2001: 28). Porém, essa centralidade do trabalho e da produção material na história dos homens não esgota em si as possibilidades de desenvolvimento da humanidade. Dessa forma, o desenvolvimento histórico do capitalismo ocorre através de pelo menos duas estratégias fundamentais, a saber: a expansão espacial do sistema - que contribui para o prolongamento dos ciclos de prosperidade entre um e outro período de crises recorrentes - e a produção de bens radicalmente novos - a partir da inovação tecnológica no seio do processo produtivo. $\mathrm{Na}$ atual fase do seu desenvolvimento, esse modo de produção agrega a estas estratégias uma dinâmica pujante. Além das questões referentes às transformações no tempo, há aquelas sobre o espaço e a espacialidade do processo de desenvolvimento das contradições inerentes ao capitalismo.

Compreendo essa espacialidade como potencialidade de transformações espaciais dos processos sociais, tendo por base uma espacialidade própria do capitalismo, sendo o espaço uma relação social ligada às configurações mais abstratas produzidas pelo desenvolvimento conjugado das forças produtivas e das relações de produção através de especificações materiais e simbólicas. O desenvolvimento do capitalismo através da 
transformação das relações sociais de produção no âmbito da modernização ${ }^{3}$ é exemplificado por Marshal Berman nos processos que demonstram seu caráter revolucionário, como: a emergência e expansão de um mercado mundial; o surgimento, a absorção e destruição de mercados locais e regionais; o caráter cosmopolita da produção e do consumo; o colapso das indústrias locais pela concorrência internacional; a escala mundial das comunicações; a maior concentração do capital; a expulsão pela força ou pela concorrência dos camponeses e artesãos de seus estabelecimentos; a centralização e a racionalização da produção em fábricas altamente automatizadas e as migrações de trabalhadores, a Revolução Científica - a transformação do conhecimento científico em tecnológico, etc. Para que essas mudanças ocorram em determinada "ordem" é preciso um processo de centralização legal, fiscal e administrativa; uma forte concentração de poder nas mãos de Estados nacionais (BERMAN, 1986: 89-90). Resumidamente, concordamos com a concepção do Materialismo Histórico de que a Modernidade configura-se sobre os processos que se desenvolveram sobre a égide da ascensão e do desenvolvimento do capitalismo, não havendo separação entre a Modernidade e a sociedade fundada pela classe burguesa.

11 O próprio nascimento do capitalismo engendrou a contradição capital e trabalho, e foi seu desenvolvimento, mediante a instituição dos mercados nacionais e, posteriormente, do mundial, que criou as condições para o acirramento da concorrência entre os vários capitais nacionais e internacionais. Portanto, é a própria natureza do capitalismo que determina a existência de crises econômicas e sociais, de guerras de conquista e de partilha do mercado mundial inerentes à sua história. 0 processo de desenvolvimento dessas crises capitalistas e o seu eterno retorno cada vez mais recorrente põem em questão os alicerces desse modo de produção de forma cada vez mais radical. É nessas crises que grande parte das forças produtivas é sistematicamente destruída, logo após dando lugar a outras que aperfeiçoam a exploração sobre o trabalho; novos mercados são conquistados e outros são explorados de maneira mais aperfeiçoada. Em alguns momentos históricos, essas crises constituem-se como uma importante fonte de rejuvenescimento e força do sistema capitalista através do expurgo dos capitalistas tidos como incompetentes pelo mercado. É através do processo de desenvolvimento das contradições inerentes ao capitalismo que Marx melhor desenvolve as questões sobre o espaço e a espacialidade de sua teoria ao dissecar os imbróglios ideológicos da divisão social do trabalho.

12 As características do espaço urbano, com seu crescimento e sua concentração de atividades econômicas e de trabalhadores, incrementam o desenvolvimento das relações capitalistas através de uma maior circulação de mercadorias, maior rotatividade do ciclo do capital e uma aglomeração de atividades e trabalhadores que são fundamentais para o processo de acumulação. Para Marx, a cidade desempenha um papel primordial enquanto espaço único de produção e de comercialização para o desenvolvimento do capitalismo.

O MPC possui como força propulsora a acumulação de capital. Devido a esse caráter intrínseco, o processo de acumulação de capital necessita expandir a produção de maisvalia, os meios de produção, a massa assalariada, a circulação de mercadorias e o controle da classe capitalista. Para isso, o desenvolvimento das forças produtivas capitalistas necessita instituir uma territorialização própria modificando os territórios preexistentes a partir de uma espacialidade própria. Essa espacialidade constitui sua peculiaridade não somente através da concretude visível de seus elementos, mas também dos processos políticos e ideológicos que contribuem para sua formatação. Lefèbvre (1999) afirma que a 
própria sobrevivência do capitalismo está baseada na criação de uma espacialidade cada vez mais abrangente, instrumental, e, também socialmente mistificada, escondida da visão crítica sob véus espessos de ilusão e ideologia. É esse espaço que produz a reprodução das relações de produção, introduzindo nela suas contradições múltiplas.

Conforme o conceito de espacialidade explicitado acima, assumimos o conceito de espaço como uma relação social que expressa sincronia entre os corpos, objetivada de diversas formas - espaço geográfico, território e região - através de especificações materiais e simbólicas. Assim, o espaço geográfico é produto, condição e meio para a reprodução das relações sociais no sentido amplo da reprodução da sociedade (CARLOS, 1999: 63) e o território é o produto dos atores sociais. São esses atores que produzem o território, partindo da realidade inicial dada, que é o espaço (RAFFESTIN, 1993: 7).

Território é um espaço onde se projetou um trabalho, seja energia e informação, e que, por consequência, revela relações marcadas pelo poder. Ao mesmo tempo é objeto de consumo, instrumento político e elemento integrante da luta de classes e das forças produtivas como "design espacial" que pode ser convertido em mercadoria. Desse modo, a teoria do espaço consiste em uma determinada especificação de uma teoria mais ampla da organização da sociedade e de sua forma espacial de existência. A proposta de Lefèbvre consiste em desvelar a produção atual do espaço através da concepção de várias formas e modalidades de gênese espaciais.

16 A análise que realiza tem em conta que o espaço não é simplesmente um elemento cultural que faz parte da superestrutura da sociedade e, de modo corolário, que a urbanização não é um simples somatório de elementos. Nas palavras de Limonad (1999:72), para Lefèbvre o espaço não se resumiria a um reflexo das relações sociais de produção e a urbanização [...] deveria ser entendida enquanto expressão das relações sociais ao mesmo tempo em que incidiria sobre elas. Não reduz o espaço a um mero meio de produção, pois considera-o digno de fazer parte das forças produtivas. Sua propriedade confere uma posição privilegiada na estrutura econômica, bem como seu controle pode gerar ganho econômico ao ser preenchido com algo produtivo ou ao ser atravessado por produtos. A afirmativa lefèbvriana de que as relações sociais se concretizam enquanto relações espaciais fundamenta uma forma peculiar de compreensão do espaço social na qualidade de condição e produto das relações sociais enquanto necessidade e condição prévia de toda atividade social, isto é, como uma força produtiva de que o capital se apodera para criar as condições de sua reprodutibilidade. Além disso, os homens, ao produzirem os meios de vida e os meios indispensáveis à sua reprodução como espécie, produzem um determinado espaço geográfico. Porém, o espaço assim produzido depende do momento histórico específico do desenvolvimento das forças produtivas, ou seja, o espaço é produzido na busca de uma funcionalidade que procura maximizar o processo produtivo da sociedade de forma geral. Esse cenário de imbricação entre o espaço geográfico, entendido como produto, condição e meio para a reprodução das relações sociais, e a sociedade é o foco de análise para Lefèbvre. Assim, as relações espaciais impregnam o MPC simultaneamente como produto e produtor, relação e objeto de forma dialética. Em uma sociedade fundada em relações de produção capitalistas, o processo de acumulação produz e reproduz espaços fragmentados que são apropriados na forma de mercadoria.

17 O espaço, desse modo constituído, articula duas dimensões: uma que se refere à localização geográfica em si e outra que se refere ao conteúdo específico dessa localização. Esse conteúdo é determinado pelas relações sociais que se estabelecem nesse 
espaço e, portanto, confere a ele a característica de produto social e histórico. Lefèbvre aponta que o capitalismo sobreviveu como sistema ao produzir seu próprio espaço. Assim, a apropriação, o controle e o domínio dos espaços impõem comportamentos, gestos e modelos de construção que contribuem para o processo de acumulação capitalista através da especialização dos lugares que são direcionados a determinados fluxos e usos, produzindo sempre "novas centralidades".

Para Lefèbvre, a cidade é o lugar mais especializado para o desenvolvimento do processo de acumulação capitalista, desempenhando uma centralidade de natureza específica. Entretanto, essa centralidade não é indiferente ao que ela reúne, ao contrário, pois ela exige um conteúdo (LEFÈBVRE, 1999: 110), e a cidade, por reunir em um mesmo espaço os principais elementos necessários ao desenvolvimento das forças produtivas e das relações sociais de produção capitalistas, é o seu locus privilegiado. Harvey (1982: 6-7) também aponta que a sociedade capitalista precisa, por necessidade, criar uma paisagem física uma massa de recursos físicos construídos pelo homem à sua própria imagem, apropriada, em linhas gerais, às finalidades da produção e do consumo. Mas também argumentarei que esse processo de criação do espaço é cheio de contradições e tensões e que as relações de classes nas sociedades capitalistas geram inevitavelmente fortes conflitos e correntes cruzadas.

Lefèbvre aprofunda a análise dessa espacialidade própria do capitalismo ao acrescentar que, nesse modo de produção, o papel da cidade é o de contribuir para o desenvolvimento das forças produtivas, da produtividade do trabalho e do incremento das técnicas. Nesse sentido, a cidade se constitui como uma forma de socialização das forças produtivas que concentra as condições gerais da reprodução capitalista - da produção e circulação do capital, e da reprodução da força de trabalho - como o suporte dos objetos materiais incorporados ao solo. Também seguindo esse raciocínio, Santos (1992) aponta que quanto maior o desenvolvimento das forças produtivas, maior deverá ser o nível de especialização do território onde elas se desenvolvem. Essa especialização segue as bases da divisão territorial do trabalho e desenha uma nova geografia regional, além de ter sua complexidade ligada à diversidade e às exigências do processo de produção. No caso investigado, a região da $\mathrm{BC}$ configura uma geografia regional própria, apesar dos impactos oriundos da atividade petrolífera ocorrer de forma díspare entre os municípios. Além da construção de uma espacialidade própria para perpetuar a sobrevivência do capitalismo, este domina o trabalho não somente no local de sua realização, mas também no espaço de viver da classe trabalhadora, através da definição da qualidade e dos padrões de vida da força de trabalho, em parte pela criação de ambientes construídos que se adaptem às exigências da acumulação e da produção de mercadorias (HARVEY, 1982: 20).

Procuraremos compreender como o desenvolvimento das atividades de E\&P engendrou uma determinada espacialização e especialização capitalista, em que o município de Macaé assumiu posição polar e, por conseguinte, configurou-se em uma importante centralidade econômica e territorial no ERJ a partir da segunda metade dos anos 1990.

As transformações ocorridas no território da $\mathrm{BC}$ e, particularmente, de Macaé com a chegada da PETROBRAS e das empresas prestadoras de serviços à atividade de E\&P constituem excelentes fenômenos à análise da construção e das contradições de um espaço social pelas relações sociais de produção capitalista, no caso em questão, o desenvolvimento e a expansão das atividades da indústria de P\&G. Transformações decorrentes da qualificação desse espaço (BC) aos interesses da principal empresa operadora dessa bacia sedimentar provocando um processo de desterritorialização/re- 
territorizalização através de uma verdadeira modernização ou corporatização do território (SANTOS, 1999: 201) $)^{5}$.

\section{O DESENVOLVIMENTO DA BACIA DE CAMPOS} conceito. Alguns apontam que é formada pelos municípios da Zona de Produção Principal de Petróleo (Armação dos Búzios, Cabo Frio, Campos dos Goytacazes, Carapebus, Casimiro de Abreu, Macaé, Quissamã, Rio das Ostras e São João da Barra) - definida pela Agência Nacional de Petróleo e Biocombustíveis (ANP) -, outros acham que se estende do município de Arraial do Cabo até São João da Barra. Há ainda aqueles que incluem até municípios que não possuem litoral, como Conceição de Macabu, cuja abrangência estaria na zona de influência da Bacia de Campos. Enfim, a Petrobras designa-a como uma formação geológica, ou seja, uma bacia sedimentar localizada no subsolo marinho que se estende entre os municípios de Arraial do Cabo/RJ até praticamente a cidade de Vitória, no Espírito Santo. própria para a $\mathrm{BC}$ construída a partir da definição da Zona Principal de Produção, extendendo-se através da uma configuração de uma área contínua somente formada pelos municípios litorâneos do ERJ que recebem o maior volume de royalties oriundos da produção de $P \& G$ desta bacia sedimentar. Sendo assim, é formada pelos seguintes municípios: Arraial do Cabo, Armação dos Búzios, Cabo Frio, Campos dos Goytacazes, Carapebus, Casimiro de Abreu, Macaé, Quissamã, Rio das Ostras, São Francisco de Itabapoana, São João da Barra e São Pedro da Aldeia. Resumindo, compreende-se a BC composta pelos municípios considerados "produtores" de petróleo, pelos municípios confrontantes com áreas leiloadas pela ANP diante do mar territorial da BC no ERJ.

Decorridos 40 anos de produção de $\mathrm{P} \& \mathrm{G}, \mathrm{a} B C$ ainda apresenta um vigor à atividade petrolífera e uma perspectiva de aumento da produção devido ao seu grande potencial ainda inexplorado, comprovado pelo recente interesse da Petrobras e dos principais players internacionais ao adquirirem novas áreas para exploração nos últimos leilões da ANP, e pelos projetos e revitalização dos campos maduros.

Os dados recentes da ANP (2019) indicam que a produção brasileira de petróleo alcançou em fevereiro 3.18 milhões de boe/dia em 317 campos produtores, sendo ERJ o maior produtor com 2,19 milhões de boe/dia em 38 campos (todos offshore), sendo $73 \%$ da produção de petróleo e $53 \%$ da de gás natural em relação ao total nacional. A BC produziu 1.14 milhão de boe/dia (41\%) em 39 campos produtores (incluídos os confrontantes om o 
litoral do Espírito Santo), enquanto a Bacia de Santos produziu 1.74 milhão de boe/dia (54\%) em 16 campos. A Petrobras detém a hegemonia da produção nacional com 92,9\%, mas tudo indicando uma maior participação relativas de outras empresas no futuro.

\section{A Formação do Cluster Petrolífero em Macaé e as Oportunidades de sua Expansão}

A instalação da base operacional da Petrobras em Macaé (1979), a consequente instalação de um parque de fornecedores de prestação de serviços para suprir as necessidades de apoio à produção offshore da cadeia petrolífera $\mathrm{da} \mathrm{BC}, \mathrm{o}$ aumento da produção de petróleo e gás natural e do volume de recursos provenientes dos royalties e das participações especiais provocaram diversas transformações e mudanças no cotidiano das cidades da região. Após a instalação da referida base operacional e do desenvolvimento de suas atividades, Macaé passou por um processo de profunda transformação, oriundo da instalação de um tecido de serviços industriais especializados no suporte aos serviços offshore.

$\mathrm{Na}$ verdade, há um amplo e complexo conjunto de deslocamentos de pessoas, mercadorias, capital e informação sobre [esse] o espaço geográfico (CRESPO, 2003: 245), provocando uma assimetria entre os municípios da BC. Esse processo propiciou um aumento da densidade empresarial em Macaé, tornando-a uma cidade com elevado número de empresas, enquanto os outros municípios mantiveram suas características tradicionais de balneários turísticos e/ou de municípios voltados para a pesca e a agropecuária. Somente após 30 anos de produção na BC essa atividade econômica iniciou um processo de transbordamento para outros municípios do entorno de Macaé, principalmente para Rio das Ostras e Campos dos Goytacazes.

30 A presença das principais empresas globais fornecedoras de equipamentos complexos de alta tecnologia e prestadoras de serviços petrolíferos no território de Macaé, permite o exercício de uma das faces da citada centralidade, incrementada pelas conexões internacionais dessas empresas e dos profissionais envolvidos nas operações.

Figura 1

\section{Mercado de Exploração e Produção (E\&P)}

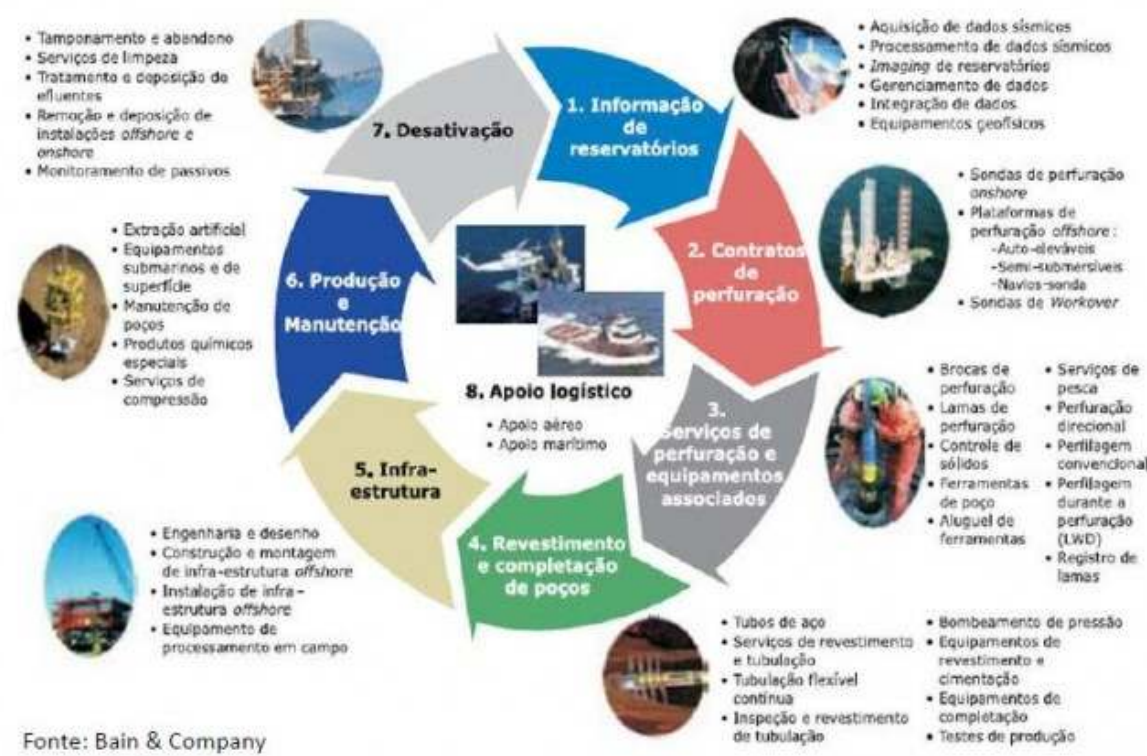


31 Na figura 1 estão as fases da etapa de E\&P e alguns dos respectivos segmentos que compõem a cadeia produtiva de suprimentos instalada em Macaé e nos municípios vizinhos.

Os resultados dos últimos leilões da ANP evidenciam o interesse das principais empresas petrolíferas do mundo em atuar no Brasil, tanto na BC como em outras fronteiras exploratórias próximas - Bacia de Santos, Foz do Amazonas, Sergipe-Alagoas, Guiana. O desafio do cluster de Macaé é manter sua hegemonia de locus privilegiado pela alta especialização ao atender esses novos mercados. Tradicionalmente as empresas internacionais possuem essa cultura de atuar novos mercados, mas as pequenas e médias empresas nacionais - que compõem o maior número dos fornecedores da região - terão dificuldade de ampliar sua atuação. Assim sendo, novos espaços especializados no suprimento das demandas offshore podem rivalizar com a centralidade que Macaé possui na indústria petrolífera nacional.

Outro elemento relevante é que devido à falta de infraestrutura portuária, as oil companies não conseguirão realizar suas operações por Macaé, mas provavelmente pelos portos do Rio de Janeiro, Niterói e Açu.

\section{A Mudança da Centralidade Regional}

34 A região Norte Fluminense sempre foi polarizada política e economicamente por Campos dos Goytacazes. Esse município possui o maior território e população e, até o declínio da atividade canavieira, a maior dinâmica econômica do interior fluminense. Assim, toda a estrutura pública formada por estabelecimentos das burocracias federal e estadual na sempre estiveram nessa cidade. Silva Neto, Dias \& Barral Neto (2008) apontam que, ao longo do tempo, Campos dos Goytacazes consolidou sua centralidade como tradicional centro regional do interior do ERJ através da concentração de grande parte da riqueza e da prestação de serviços do Norte e Noroeste Fluminenses. Essa riqueza foi consequência do crescimento econômico promovido pelo Setor Sucroalcooleiro quando este era um dos principais produtores do país. Entretanto, apesar desse setor entrar em decadência a partir da década de 1950, Campos continua a se manter como principal polo regional devido ao exercício dessa centralidade por muitas décadas.

Centralidade que também pode ser atribuída à quase ausência de crescimento, importância econômica e política dos municípios circunvizinhos, formados em sua maioria por pequenas cidades com agropecuária extensiva e de baixa produtividade, gerando pouco dinamismo econômico. Entretanto, o início das atividades de E\&P na BC desencadearam um processo de descentralização de algumas atividades e funções que antes somente eram exercidas em Campos.

Em termos de dinâmica econômica, os trunfos do jogo estão na pujança econômica de Macaé, fazendo com que a centralidade deste se fortaleça em detrimento da daquele município. Devido a pujante economia, há um claro processo de divisão da centralidade regional em direção à Macaé em detrimento da histórica centralidade desempenhada por Campos. Essa mudança ocorre a partir do que Raffestin (1993: 188) conceitua como nodosidade, que possivelmente constituem uma nova centralidade. Aponta, ainda, algumas considerações sobre a relação entre centralidade e marginalidade - se definem uma em relação à outra e são especificamente relacionais, ou seja, podem se inverter no território, sem que o mecanismo seja questionado: a centralidade pode se tornar marginalidade e vice-versa, num dado lugar. 
37 Nesse sentido, entendemos que a consolidação de Macaé, através da singularidade de concentrar as atividades da cadeia petrolífera na BC, inicia um processo de desterritorialização através de um esvaziamento de Campos dos Goytacazes, que possuiu historicamente maior importância política e econômica na região Norte Fluminense. Assim, este exercia uma influência como centro gravitacional (centralidade) por sediar algumas instituições e departamentos das burocracias estadual e federal. Há alguns anos, ocorre um processo de reterriorialização em torno de Macaé, devido à sua dinâmica econômica pela instalação da Petrobras e das empresas fornecedoras da cadeia petrolífera, à grande migração diária de trabalhadores para as empresas ali instaladas e ao crescimento maior dos seus municípios circunvizinhos em relação aos municípios do entorno de Campos dos Goytacazes, que parecem ter se adaptado melhor ao novo contexto regional oriundo das rendas petrolíferas.

Nota-se que após os anos de 2010, os investimentos para construção do Porto do Açu, em São João da Barra, e as empresas ali instaladas, favorecem um contra movimento da reterriorialização de Macaé com o aumento da importância do entorno de Campos dos Goytacazes em relação à atração de investimentos.

o processo em andamento do binômio centralidade-marginalidade entre Campos e Macaé aponta algumas questões aparentemente contraditórias a serem observadas: 1) esse processo de inversão da centralidade entre Campos e Macaé pode aumentar as disparidades intrarregionais, pois alguns municípios - por exemplo, do entorno de Macaé - se adaptam melhor ao novo contexto econômico, político e social da região; 2) o processo de transbordamento dos impactos positivos e negativos da instalação da cadeia produtiva petrolífera em direção aos outros municípios, além de Macaé, pode contribuir para reduzir e/ou aprofundar as desigualdades entre municípios ou no interior de cada um; 3) esse processo também evitaria a constituição de uma "centralidade pura" em Macaé, o que é salutar para a região e para o próprio município de Macaé, pois diminuiria os impactos provenientes da situação de "eldorado", como grande afluxo de empresas e migrantes, aumento das mazelas sociais e de desgaste da infraestrutura e dos equipamentos urbanos, etc.

40 Aparentemente contraditório é o fenômeno que ocorre em Macaé, que, apesar de vivenciar uma intensificação de sua centralidade regional a partir do seu dinamismo econômico, experimenta um processo de falta de centralidade decisória da Petrobras, das multinacionais e de grandes empresas brasileiras. Essa falta de centralidade decisória é proveniente da ausência das matrizes dessas empresas no território de Macaé, pois suas matrizes estão fora da cidade e mesmo do país, em cidades que exercem o papel de centro de comando do processo de valorização do capital no que tange à indústria do petróleo (Houston/EUA, Aberdeen/Escócia, Dubai/EAU, Stavanger/Noruega, Londres/Inglaterra e, no caso da Petrobras, Rio de Janeiro e Brasília), havendo, com isso, uma falta de autonomia em relação às principais decisões de investimento dessas empresas no município.

41 Hoje, as centralidades política e cultural ainda são exercidas por Campos dos Goytacazes, e a econômica por Macaé. Porém, os investimentos que aportam na região (por exemplo, no Porto do Açu) provavelmente contribuirão para a consolidação desse processo de descentralização regional, constituindo duas centralidades: a exercida pelo município de Campos dos Goytacazes e outra por Macaé. Entretanto, a tendência é que no entorno dessas nodosidades, desenvolvam-se as cidades menores, devido ao incremento das atividades econômicas provenientes dos novos investimentos e da própria dinâmica das 
inversões da cadeia produtiva de P\&G. Assim, espera-se o aprofundamento do processo de transbordamento da dinâmica econômica em direção aos outros municípios, que não somente Rio das Ostras e Campos dos Goytacazes. Somente no futuro veremos como se consolidará essa relação centralidade-marginalidade entre os dois municípios e como será o posicionamento dos municípios dos seus respectivos entornos em relação ao contexto de atração de investimentos.

\section{0 Transbordamento das Atividades Petrolíferas}

42 A partir dos anos 2010, ou seja, somente após 30 anos de início da produção de $P \& G$ em águas da $\mathrm{BC}$, inicia-se um processo de transbordamento da aglomeração produtiva em direção aos outros municípios, que se mostraram mais agressivos e eficazes na atração de investimentos e de algumas oportunidades trazidas pela proximidade à economia do petróleo. Isso também acontece pelo agravamento das consequências das chamadas deseconomias de aglomeração que começaram a se intensificar em Macaé. A infraestrutura é precária no que tange ao fornecimento de água, energia elétrica, internet e telefonia fixa. Além disso, as ruas suportam um trânsito pesado de caminhões e carretas carregados com equipamentos entre as empresas e os principais pontos de apoio logístico - o porto de Imbetiba, o Parque dos Tubos e a saída para a BR-101-, ocasionando constante degradação da malha rodoviária urbana. Além disso, o aumento da violência urbana, da mendicância, da favelização e dos congestionamentos são outros efeitos da aglomeração de pessoas e empresas e da migração proveniente da imagem de "eldorado" que atraiu e ainda atrai inúmeros migrantes ${ }^{6}$.

43 Com objetivo de não estarem à margem do crescimento econômico promovido pela dinâmica da indústria petrolífera, alguns municípios desenvolveram algumas vantagens comparativas com o objetivo de atrair investimentos para seus territórios. Em escala e escopo diferenciados, os municípios de Rio das Ostras, Quissamã e Carapebus oferecem distritos industriais conhecidos como Zonas Especiais de Negócios com benefícios fiscais e infraestrutura para atrair empresas ligadas ou não a essa cadeia produtiva.

Dessa forma, Rio das Ostras demonstra maior adaptabilidade à dinâmica e às exigências da cadeia petrolífera, pois possui a melhor experiência na atração de investimentos. A ZEN constituiu uma área de 1 milhão de metros quadrados com fornecimento de infraestrutura - terreno com baixíssimo custo, terraplanagem, energia elétrica, água e saneamento básico, pavimentação, gás natural, telefonia por fibra ótica, internet em banda larga e centro de qualificação profissional - adequada à instalação das empresas e redução de 2,5\% para 2,0\% das alíquotas do ISS. Os lotes estão estrategicamente localizados junto ao limite do município de Macaé e da base Parque de Tubos da Petrobras, no qual são concedidos às empresas por 15 anos com possibilidade de renovação e isentos da cobrança do IPTU. A contrapartida das empresas é a contratação de até $80 \%$ da sua força de trabalho no município, quando houver disponibilidade de trabalhadores qualificados para as funções requeridas pelas empresas.

A principal estratégia de atração de investimentos realizada pelo município de Campos dos Goytacazes foi o Fundo de Desenvolvimento de Campos (Fundecam) criado em 2002. Esse fundo promoveu linha de financiamento público para investimentos com taxa de $6 \%$ ao ano com um ano de carência mais cinco anos para pagamento.

Além disso, os investimentos no Complexo do Açu transbordam seus efeitos para Campos, pois os municípios de São João da Barra (sede do empreendimento) e São Francisco de Itabapoana não conseguirão suportar a demanda por fornecimentos contínuos e em 
quantidades crescentes que esse empreendimento exige e exigirá com a instalação de novas empresas.

\section{Novas Fronteiras Exploratórias}

A Bacia de Santos (54\%) suplantou em 10 anos a BC (41\%) como maior província produtora do Brasil. Mesmo que parte das operações sejam realizadas por Macaé e atendidas por empresas instaladas no município, necessariamente há uma migração de parte das atividades para outras regiões que poderão rivalizar no futuro com Macaé em relação à centralidade exercida pela especialidade operacional.

Além da BS, nos últimos anos o mercado offshore brasileiro recebeu notícias positivas com bastante constância, principalmente através dos leilões de novas áreas disponibilizadas pela ANP, atraindo um número elevado de grandes empresas petrolíferas nacionais e internacionais.

Nos últimos meses, notícias positivas surgiram para mostrar que as empresas da BC devem se preparar e aproveitar não somente as novas oportunidades no país (Bacia de Sergipe-Alagoas, pré-sal e atividades recuperação dos campos maduros na Bacia de Campos), mas também as que estão surgindo nos países vizinhos, principalmente na Guiana e na Argentina.

As atividades na Guiana estão mais avançadas através do desenvolvimento do projeto de Liza. Desde quando começou a operar no país, a ExxonMobil aumentou para 4 bilhões de barris de boe em recursos recuperáveis para o bloco Stabroek. Na vizinha Argentina além do potencial das áreas não convencionais, principalmente em Vaca Muerta, o governo argentino realizou um leilão recente de 38 áreas offshore nas bacias de Austral Norte, Oeste de Malvinas e Argentina Norte, sendo que 18 foram arrematadas com bônus de US\$ 995 milhões. Este leilão atraiu os principais players internacionais, tais como: Mitsui, BP, ENI, Tullow, QPI, Equinor, ExxonMobil, Total, YPF, Shell, Pluspetrol, Tecpetrol e Winteershall. Sendo que possuem atuação no Brasil a Equinor, BP, ExxonMobil, Total, Shell, o que pode facilitar a entrada de fornecedores brasileiros neste mercado, pois alguns deste já atuam com estas petroleiras. Internamente, a bacia de Sergipe-Alagoas é apontada como uma província petrolífera promissora para o futuro próximo.

51 As empresas fornecedoras macaenses e da região da BC devem acompanhar as atividades e os projetos dessas regiões para buscar suprir com bens e serviços essas regiões, pois é uma chance de diversificar a carteira de clientes, o portfólio, realizar parcerias com empresas estrangeiras e ganhar know how com a exportação de bens e serviços e, principalmente, diminuir à exposição a oscilação do mercado nacional e a dependência dos investimentos da Petrobras. Além, claro, de manter a região da $\mathrm{BC}$ como centro da atividade de E\&P no Brasil, mesmo que as empresas instaladas atuem em outros mercado e regiões.

\section{CONSIDERAÇÕES FINAIS}

Diante das questões anteriormente apontadas, tanto o município de Macaé como a região da Bacia de Campos estão em um processo de perda de centralidade ou, como outros preferem, de hegemonia sobre a indústria petrolífera no Brasil.

Faz-se necessário urgentemente uma discussão da sociedade desses territórios em como reverter esse processo, mesmo que a expertise operacional ainda se concentre em Macaé e região, mas os aspectos de decisões estratégicas não se encontram nele, bem como a 
ultrapassagem pela Bacia de Santos em termos de produção, tornando-se a mais relevante do Brasil.

\section{BIBLIOGRAFIA}

ANP. Boletim de Produção de Petróleo e Gás Natural. Fevereiro/2019, número 102, retificado em 25/04/2019. www.anp.gov.br. Consultado em 01/05/2019.

ARAUJO, Frederico Guilherme Bandeira. Saber sobre os homens, saber sobre as coisas: história e tempo, geografia e espaço, ecologia e natureza. Rio de Janeiro: FAPERJ/DP\&A Editora, 2003, 368 p.

BERMAN, Marshall. Tudo que é sólido se desmancha no ar - a aventura da modernidade. São Paulo: Companhia das Letras, $1986,360 \mathrm{p}$.

CARLOS, Ana Fani Alessandri. “'Novas' contradições do espaço”. In: DAMIANI, Amélia Luisa; CARLOS, Ana Fani Alessandri \& SEABRA, Odette Carvalho de Lima. O espaço no fim de século - a nova raridade. São Paulo: Contexto, 1999, 220 p.

CRESPO, Nelson. "E Campos dos Goytacazes perde a corrida do petróleo". In: PIQUET, Rosélia. Petróleo, royalties e região. Rio de Janeiro: Garamond, 2003, p. 239-256.

HARVEY, David. O trabalho, o capital e o conflito de classes em torno do ambiente construído nas sociedades capitalistas avançadas. Revista Espaço \& Debate, 1982.

LEFÈBVRE, Henri. A cidade do capital. Rio de Janeiro: DP\&A, 1999, 180 p.

LIMONAD, Ester. Reflexões sobre o espaço, o urbano e a urbanização. In: GEOgraphia, a. I, n. 1. Revista da Pós-Graduação em Geografia. Niterói: UFF, 1999.

LIPIETZ, Alain. O Capital e seu espaço. São Paulo: Nobel, 1988, 210 p.

MARX, Karl \& ENGELS, Friedrich. Manifesto do Partido Comunista. In: FILHO, Daniel Aarão. 0 Manifesto Comunista - 150 anos depois. Rio de Janeiro: Fundação Perseu Abramo/Contraponto, 1998, p. 7-41.

MARX, Karl \& ENGELS, Friedrich. A Ideologia alemã (Feuerbach). São Paulo: Hucitec, 11.ed., 1999, $138 \mathrm{p}$.

NADER, Glauco. Pós-Modernidade e Espaço: reflexões sobre a proposição do Materialismo Histórico e Geográfico de Edward Soja. Dissertação de Mestrado em Planejamento Urbano e Regional, 2002, 135 p.

NADER, Glauco. 0 posicionamento estratégico de Macaé no desenvolvimento do Estado do Rio de Janeiro. Tese de Doutorado em Planejamento Urbano e Regional, IPPUR/UFRJ, 277 p., 2009.

NADER, Glauco. Oportunidades em novas fronteiras exploratórias.

www.energiaquefalacomvoce.com.br. Reed Alcantara. Acessado em 02/05/2019.

OSÓRIO, Mauro. Rio Nacional, Rio Local - mitos e visões da crise carioca e fluminense. Rio de Janeiro: Senac Rio, 2005, 296 p.

PAULA, João Antônio de (2001): O marxismo como pensamento crítico. Revista da Sociedade Brasileira de Economia Política n. 9. Rio de Janeiro: 7 Letras, p. 24-52. 
RAFFESTIN, Claude. Por uma geografia do poder. São Paulo: Ática, 1993, 269 p.

SANTOS, Angela Moulin S. Penalva. Prefácio. In: NATAL, Jorge (Org.). o Estado do Rio de Janeiro Pós 1995. Rio de Janeiro: Pubblicati/Faperj, 2005, p. 10-11.

SANTOS, Milton. Modernidade, meio técnico-científico e urbanização no Brasil. In: Cadernos IPPUR , a. VI, n. 1, dez. 1992, p. 9-22.

SANTOS, Milton. A natureza do espaço - técnica e tempo. Razão e emoção. São Paulo: Hucitec, 1999, $308 \mathrm{p}$.

SILVA, Romeu; DIAS, Robson Santos \& BARRAL NETO, Jayme Freitas. Campos dos Goytacazes: novas perspectivas para um tradicional centro interiorano fluminense. In: FAURÉ, Yves A; HASENCLEVER, Lia \& SILVA NETO, Romeu (Orgs.). Novos rumos para a economia fluminense: oportunidades e desafios do crescimento do interior. Rio de Janeiro: E-papers, 2008, p. 89-126.

\section{NOTAS}

1. A obra do COMPERJ está paralisada por enquanto e fora do atual Plano de Negócios da Petrobras (2018-2022). Atualmente está em andamento a construção de uma Unidade de Processamento de Gás Natural (UPGN) para processamento do gás natural oriundo do pré-sal da Bacia de Santos.

2. Nas palavras de Marx \& Engels (1998: 11): “Tudo o que era sólido desmancha no ar, tudo que era sagrado é profanado [...]".

3. “Apropriamo-nos da definição de Marshall Berman (1996), na qual a Modernidade, enquanto conceito de época histórica, é compreendida como a relação entre a modernização e o modernismo; este entendido como a esfera dos processos sociais no campo da cultura e aquela compreendida como o âmbito dos processos sociais na esfera da acumulação, das relações de produção e das forças produtivas" (NADER, 2002: 3).

4. No caso específico deste trabalho, Macaé exerce uma centralidade importante no que tange à indústria de petróleo e gás natural, porque reúne os principais elementos para seu desenvolvimento.

5. "Seguindo a conceituação de Milton Santos (1999: 83), as plataformas de petróleo não fazem parte da paisagem - "porção da configuração espacial que se pode abarcar com a visão" macaense ou da Bacia de Campos, pois estão a muitos quilômetros do litoral. Apesar disso, são elas que mais contribuem para a configuração territorial desse espaço com as necessidades de fornecimento de bens e serviços para manutenção das operações em alto mar (Nader, 2009: 29).

6. Apesar da crise econômica e do setor petrolífero dos últimos 5 anos terem refreado esse movimento migratório, nos próximos anos espera-se sua retomada a partir dos investimentos para aumento da produção de petróleo e gás.

\section{RESUMOS}

O trabalho pretende investigar o significado de nova centralidade econômica e territorial de Macaé diante dos novos empreendimentos na região da Bacia de Campos e das novas fronteiras exploratórias. A ideia é evidenciar há necessidade de um novo posicionamento e/ou de uma nova centralidade econômica e territorial de Macaé em relação ao reconhecimento como centro da 
indústria petrolífera no Brasil. Essa nova centralidade deverá ser construída a partir das características de um novo momento histórico vivenciado pelo país, pelo ERJ e pela própria indústria de $P \& G$, a saber: um mais amplo, a partir de investimentos e novas fronteiras exploratórias fora da $\mathrm{BC}$; outro de âmbito regional configurando um movimento interno na própria $\mathrm{BC}$ de "transbordamento" da dinâmica econômica dessa indústria para além das fronteiras macaenses em direção aos outros municípios, como Rio das Ostras e Campos dos Goytacazes.

Le document a pour objet d'examiner la signification de la nouvelle centralité économique et territoriale de Macaé face aux nouveaux développements de la région de la Campos Bassin et aux nouvelles frontières exploratoires. L'idée est de souligner la nécessité d'un nouveau positionnement et / ou d'une nouvelle centralité économique et territoriale de Macaé par rapport à la reconnaissance en tant que centre de l'industrie pétrolière au Brésil. Cette nouvelle centralité doit être construite sur les caractéristiques d'un nouveau moment historique vécu par le pays, l'ERJ et le secteur petrole et gez lui-même, à savoir: un moment plus large, basé sur des investissements et de nouvelles frontières exploratoires en dehors de la Campus Bassin; une autre de portée régionale configurant un mouvement interne dans la propre $\mathrm{CB}$ de "débordement" de la dynamique économique de cette industrie au-delà des frontières du Macanese vers d'autres municipalités, telles que Rio das Ostras et Campos dos Goytacazes.

El trabajo tiene como objetivo investigar el significado de la nueva centralidad económica y territorial del municipio de Macaé frente a los nuevos desarrollos en la región de la Bacía de Campos (BC) y las nuevas fronteras exploratorias. La idea es resaltar la necesidad de un nuevo posicionamiento y / o una nueva centralidad económica y territorial de Macaé en relación con el reconocimiento como el centro de la industria petrolera en Brasil. Esta nueva centralidad debería construirse a partir de las características de un nuevo momento histórico experimentado por el país, el estado de Río de Janeiro y la propia industria de $P \& G$, a saber: uno más amplio, de inversiones y nuevas fronteras exploratorias fuera del $\mathrm{BC}$; otro de alcance regional es un movimiento interno en el propio $\mathrm{BC}$ de "desbordar" la dinámica económica de esta industria más allá de las fronteras macaense hacia otros municipios, como Rio das Ostras y Campos dos Goytacazes.

The paper intends to investigate the meaning of new economic and territorial centrality of Macaé in the face of new developments in the Campos Basin region and the new exploratory frontiers. The idea is to highlight the need for a new positioning and / or a new economic and territorial centrality of Macaé in relation to recognition as the center of the oil industry in Brazil. This new centrality must be built on the characteristics of a new historical moment experienced by the country, the ERJ and the O\&G industry itself, namely: a broader one, based on investments and new exploratory frontiers outside the $\mathrm{BC}$; another one of regional scope configuring an internal movement in the own $\mathrm{BC}$ of "overflowing" of the economic dynamics of this industry beyond the borders of Macaé towards other municipalities, such as Rio das Ostras and Campos dos Goytacazes.

\section{ÍNDICE}

Palavras-chave: Bacia de Campos, Macaé, Espacialidade, Petróleo, reterritorialização.

Palabras claves: Bacía de Campos, Macaé, Espacialidad, Petróleo, reterritorialización.

Keywords: Campos Basin, Macaé, Space, Oil, reterritorialization.

Mots-clés: Campos Basin, Macaé, Space, Oil, reterritorialisation. 


\section{AUTOR}

\section{GLAUCO LOPES NADER}

Economista/UFF, Mestre e Doutor em Planejamento Urbano e Regional - IPPUR/UFRJ. Professor Colaborador do Mestrado Profissional em Engenharia de Produção e Sistemas Computacionais PURO/UFF. Diretor da Dinamus Consultoria.

E-mail: glauconader@terra.com.br. 